\title{
Chronic, nonhealing leg ulcer
}

\section{When this patient's chronic stasis ulcer failed to respond to the usual treatment of dressings, elevation, and diuretics, our suspicions led us to an unexpected diagnosis.}

AN 80-YEAR-OLD WOMAN with a history of hypertension, hyperlipidemia, psoriasis vulgaris with associated pruritus, and well-controlled type 2 diabetes mellitus presented with a slowly enlarging ulceration on her left leg of 1 year's duration. She noted that this lesion healed less rapidly than previous stasis leg ulcerations, despite using the same treatment approach that included dressings, elevation, and diuretics to decrease pedal edema.

Physical examination revealed plaques with white micaceous scaling over her exten- sor surfaces and scalp, as well as guttate lesions on the trunk, typical of psoriasis vulgaris. A $5.8 \times 7.2-\mathrm{cm}$ malodorous ulceration was superimposed on a large psoriatic plaque on her left anterior lower leg (FIGURE 1). A 4-mm punch biopsy was obtained from the peripheral margin.

\section{O WHAT IS YOUR DIAGNOSIS? \\ O HOW WOULD YOU TREAT THIS PATIENT?}

David Crasto, DO; Allison Cruse, MD; Adam Byrd, MD; Robert Brodell, MD William Carey University College of Osteopathic Medicine, Hattiesburg, MS (Dr. Crasto); Department of Dermatology (Drs. Cruse, Byrd, and Brodell) and Department of Pathology (Drs. Cruse and Brodell), University of Mississippi Medical Center, Jackson

\section{- crastodave@gmail.com}

DEPARTMENT EDITOR Richard P. Usatine, MD University of Texas Health at San Antonio

The authors reported no potential conflict of interest relevant to this article.

doi: 10.12788/jfp.0077
FIGURE 1

Malodorous ulceration superimposed on a psoriatic plaque

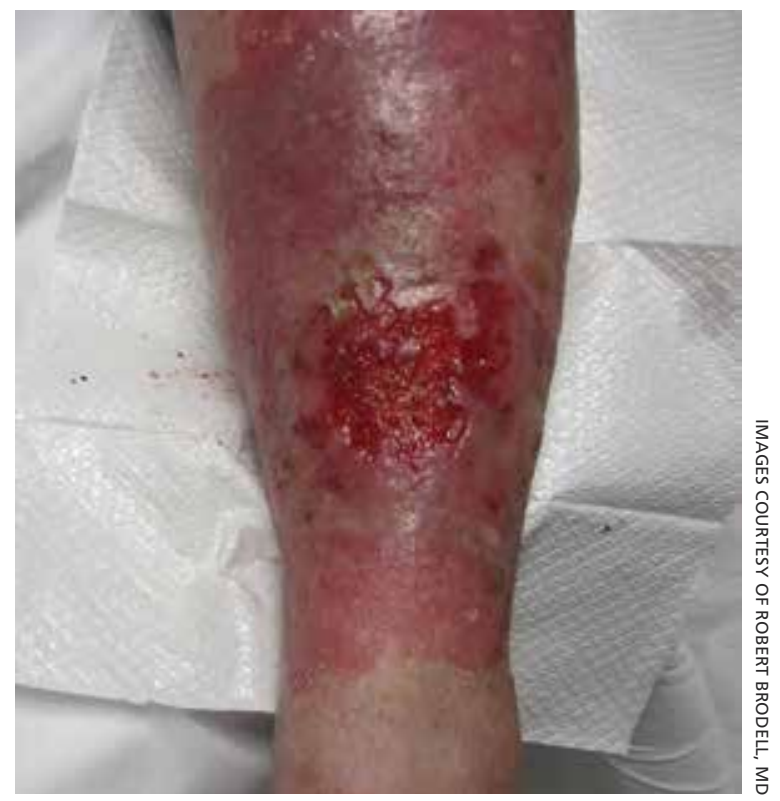

A $5.8 \times 7.2-\mathrm{cm}$ ulceration developed in an area of scaling and violaceous erythema typical of the patient's underlying psoriasis vulgaris on her left leg.

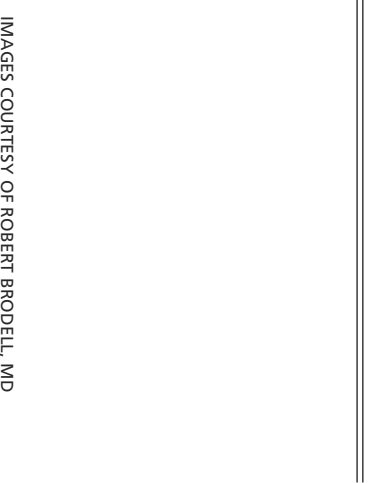




\section{Diagnosis: \\ Basal cell carcinoma}

Histopathological examination revealed elongated strands of closely packed basaloid cells embedded in a densefibrous stroma with overlying ulceration and crusting (FIGURE 2). Immunohistochemical staining with cytokeratin (CK) $5 / 6$ decorated the cytoplasm of the tumor cells, which confirmed that the tumor was a keratinocyte cancer. CK 20 was negative, excluding the possibility of a Merkel cell carcinoma. Scout biopsies from 3 additional areas of ulceration confirmed that the entire ulceration was infiltrated by basal cell carcinoma (BCC).

\section{A surprise hidden in a chronic ulcer}

More than 6 million Americans have chronic ulcers and most occur on the legs. ${ }^{1}$ The majority of these chronic ulcerations are etiologically related to venous stasis, arterial insufficiency, or neuropathy. ${ }^{2}$

Bacterial pyoderma, chronic infection caused by atypical acid-fast bacilli or deep fungal infection, pyoderma gangrenosum, cutaneous vasculitis, calciphylaxis, and venous

\section{FIGURE 2}

\section{Punch biopsy points to a keratinocyte cancer}

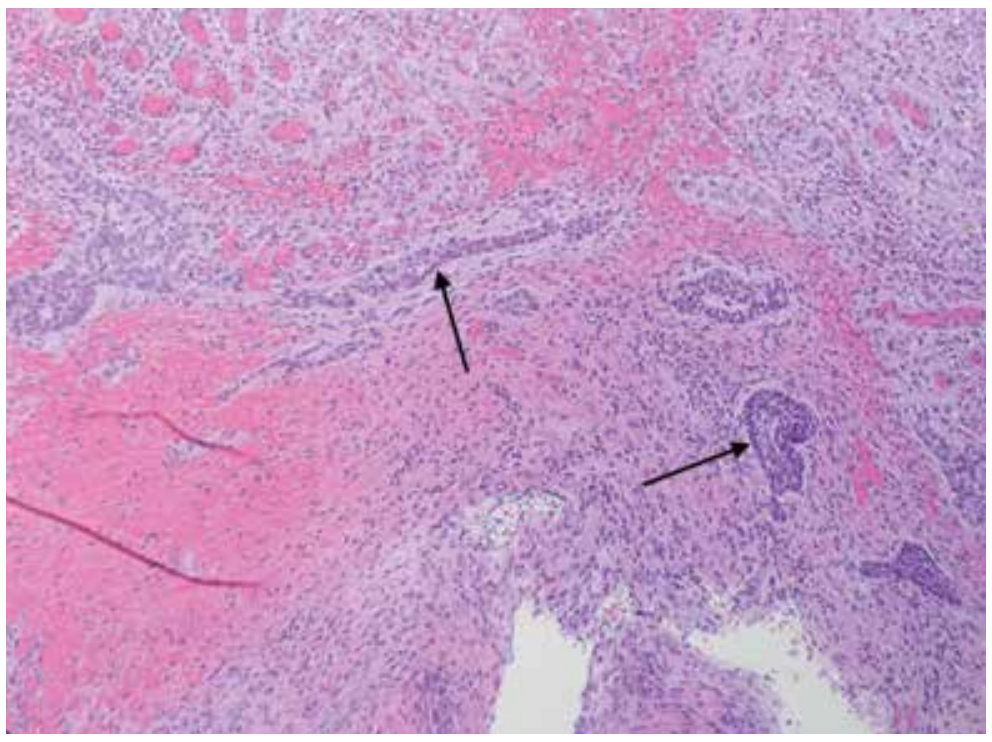

Elongated strands of basaloid cells (arrows) with surrounding chronic inflammation and fibrosis typical of basal cell carcinoma (BCC) were noted in the superficial and mid dermis beneath a thick scale crust $(H \& E$, original magnification $\times 200)$. Scout biopsies from 3 additional areas of ulceration confirmed that the entire ulceration was infiltrated by BCC. ulceration were all considered to explain this patient's nonhealing wound. A biopsy was required to fully assess these possibilities.

I Don't overlook the possibility of malignancy. In a cross-sectional, multicenter study by Senet et al, ${ }^{3} 144$ patients with 154 total chronic leg ulcers were evaluated in tertiary care centers for malignancy, which was found to occur at a rate of $10.4 \%$. Similarly, Ghasemi et $\mathrm{al}^{4}$ demonstrated a malignancy rate of $16.1 \%$ in 124 patients who underwent biopsy; the anterior shin was determined to be the most frequent location for malignancy. The most common skin cancer identified within the setting of chronic ulcers is squamous cell carcinoma. ${ }^{3}$ Although rare, there are reports of BCC identified in chronic wounds. ${ }^{3-7}$

I Morphological signs suggestive of malignancy in chronic ulcerations include hyperkeratosis, granulation tissue surrounded by a raised border, unusual pain or bleeding, and increased tissue friability. Our patient had none of these signs and symptoms. However, it is possible that she had a tumor that ulcerated and would not heal.

Which came first? It's difficult to know in this case whether a persistent BCC ulcerated, forming this lesion, or if scarring associated with a chronic ulceration led to the development of the BCC. ${ }^{6}$ Based on biopsies taken at an earlier date, Schnirring-Judge and Belpedio $^{7}$ concluded that a chronic leg ulcer could, indeed, transform into a BCC; however, pre-existing BCC more commonly ulcerates and then does not heal.

\section{Treatment options}

While smaller, superficial BCCs can be treated with topical imiquimod, photodynamic therapy, or electrodesiccation and curettage, larger lesions should be treated with Mohs micrographic surgery and excisional surgery with grafting. Inoperable tumors may be treated with radiation therapy and vismodegib.

I Our patient. Once the diagnosis of BCC was established, treatment options were discussed, including excision, local radiation therapy, and oral hedgehog inhibitor drug therapy. ${ }^{8}$ Our patient opted to undergo a wide local excision of the lesion followed by negative-pressure wound therapy, which led to complete healing. 
CORRESPONDENCE

David Crasto, DO, William Carey University College of Osteopathic Medicine, 498 Tuscan Avenue, Hattiesburg, MS 39401; crastodave@gmail.com

\section{References}

1. Sen CK, Gordillo GM, Roy S, et al. Human skin wounds: a major and snowballing threat to public health and the economy. Wound Repair Regen. 2009;17:763-771.

2. Fox JD, Baquerizo Nole KL, Berriman SJ, et al. Chronic wounds: the need for greater emphasis in medical schools, post-graduate training and public health discussions. Ann Surg. 2016;264:241-243.
3. Senet P, Combemale P, Debure C, et al. Malignancy and chronic leg ulcers. Arch Dermatol. 2012;148:704-708.

4. Ghasemi F, Anooshirvani N, Sibbald RG, et al. The point prevalence of malignancy in a wound clinic. Int J Low Extrem Wounds. 2016;15:58-62.

5. Labropoulos N, Manalo D, Patel N, et al. Uncommon leg ulcers in the lower extremity. J Vasc Surg. 2007;45:568-573.

6. Tchanque-Fossuo CN, Millsop J, Johnson MA, et al. Ulcerated basal cell carcinomas masquerading as venous leg ulcers. $A d v$ Skin Wound Care. 2018;31:130-134.

7. Schnirring-Judge M, Belpedio D. Malignant transformation of a chronic venous stasis ulcer to basal cell carcinoma in a diabetic patient: case and review of the pathophysiology. J Foot Ankle Surg. 2010;49:75-79.

8. Puig S, Berrocal A. Management of high-risk and advanced basal cell carcinoma. Clin Transl Oncol. 2015;17:497-503.

\section{PRACTICE OPPORTUNITIES}

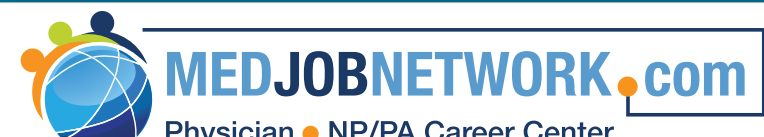

Please contact Tim LaPella to inquire about classified advertising in The Journal of Family Practice (circulation: 95,000).

Display rates are available, with a discount for frequency. Per word rate for line ads is \$5.25. Phone 484-921-5001. Fax 484-921-5005.

E-mail: tlapella@mdedge.com. Visit our Web site at mdedge.com/familymedicine; visit MedJobNetwork.com.

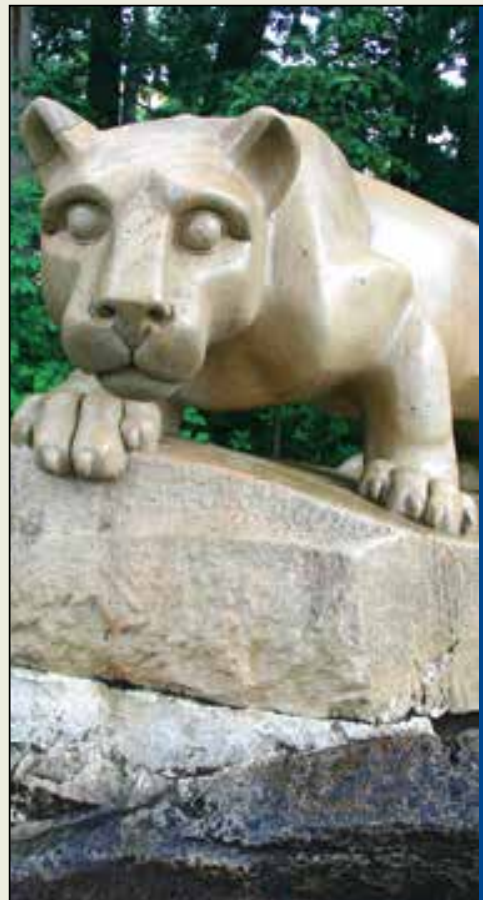

\section{Family Medicine Residency Core Faculty Physician}

Penn State Health St. Joseph Medical Center

Reading, PA

Penn State Health St. Joseph is seeking a BC/BE family medicine physician to join our team as a faculty member in our 6-6-6 Family and Community Medicine Residency Program in Berks County, PA. Priority will be given to candidates interested in inpatient medicine. The Family and Community Medicine Residency Program strives to provide excellent education in training family physicians to provide comprehensive, compassionate, coordinated and continuous high-quality patient-centered care to the community served by our Program.

Duties include teaching, mentoring, advising, and supervising residents; engaging in scholarly activity; and providing patient care. The residency program fosters a supportive family-oriented environment that encourages work-life balance.

Job Requirements

- Medical degree - M.D., D.O. or foreign equivalent

- Completion of an accredited Family Medicine residency program

- Board certification/eligibility in Family Medicine

- Experience in an academic setting preferred

- Conversational Spanish speaking skills preferred

\section{PennState Health}

TO APPLY, PLEASE SEND YOUR CURRICULUM VITAE (CV) TO:

Greg Emerick, MHA, FASPR - Physician Recruiter

Department of Human Resources - Penn State Health

E-mail: gemerick@pennstatehealth.psu.edu • Phone: 717-531-4725 